\title{
Considerações sobre o conto simoniano - a singularidade de Chasque do Imperador
}

\author{
Carlos Túlio Medeiros* \\ Cláudia Lorena Fonseca**
}

\begin{abstract}
Resumo: "Chasque do Imperador" encontra-se entre as narrativas menos conhecidas e estudadas dos Contos gauchescos, de João Simões Lopes Neto, obra que se constitui em importante legado da Literatura de expressão regional gaúcha. $\mathrm{O}$ autor começa a ser reconhecido fora do circuito da literatura regional, sendo apontado, inclusive como precursor de João Guimarães Rosa, sobretudo no que se refere aos aspectos formais de sua obra. João Simões Lopes Neto possui vasta fortuna crítica e novos estudos são empreendidos, além disso, 'descobertas' são feitas constantemente, tendo ambos, autor e obra, por objeto. Este estudo tem por objetivo abordar aspectos específicos da construção de "Chasque do Imperador", dada a sua singularidade, e a forma como ele se insere no conjunto dos Contos gauchescos.
\end{abstract}

Palavras-chave: regionalismo; João Simões Lopes Neto; Contos gauchescos.

\begin{abstract}
Chasque do Imperador" is one of the tales which holds little prestige among readers, in spite of the fact that it belongs to the book Contos Gauchescos, by João Simões Lopes Neto, which is an important expression of the regional Literature. When the writer João Simões Lopes Neto began to be recognized outside of his own region, the literary critics considered him to be a kind of precursor of João Guimarães Rosa, especially when the focus is the formal aspects of Neto's literary work. João Simões Lopes Neto has a huge critical reception and constantly new studies are carried out about himself and his work, especially about the tale "Chasque do Imperador". This paper aims to study specifically how the tale was created and written and how it was inserted into the whole structure of Contos Gauchescos.
\end{abstract}

Keywords: regionalism; João Simões Lopes Neto; Contos gauchescos..

Cada vez mais considerada nos meios literários, a obra de João Simões Lopes Neto, dada a sua representatividade, não apenas dentro do sistema literário regional ao qual se filia, mas também pelo valor que adquiriu no âmbito da literatura brasileira de maneira geral, devido aos estudos empreendidos sobretudo por aqueles que se dedicam à obra do mineiro João Guimarães Rosa, os quais destacam a proximidade desta com a do autor gaúcho, no que se refere a aspectos formais e temáticos, tem sido objeto de análise já há algum tempo por

\footnotetext{
* Carlos Túlio Medeiros é mestrando em Literatura Comparada na UFRGS.

** Cláudia Lorena Fonseca é doutoranda em Literatura Comparada na UFRGS.
} 
parte dos estudiosos gaúchos. Esses estudos, que hoje estão voltados a aspectos não tão evidentes e à produção menos conhecida do autor, retomam também, continuamente, a obra que primeiro despertou o interesse de leitores e teóricos: os Contos gauchescos (1983a).

Constituindo-se em um conjunto de narrativas, os Contos tratam da saga do narrador, Blau Nunes, cuja trajetória se apresenta intrinsecamente relacionada ao período da História do Rio Grande do Sul correspondente ao tempo de sua vida. São, em geral, contos de forte apelo dramático, os quais, ao mesmo tempo em que contam a saga de Blau, narram episódios da História do Rio Grande do Sul, em um período marcante do ponto de vista histórico, social e também geográfico - já que as fronteiras se fixam -, não só do estado como do país, além de servir de inventário e memória da região que se transforma. As referências históricas perpassam a obra, especialmente as batalhas que tiveram esse estado por cenário, entre as quais a Revolução Farroupilha. Personagens históricas também se fazem presentes, bem como determinados fatos, contados pelo narrador, que de alguns deles acaba 'participando', como testemunha da História.

Porém, se no conjunto dos contos que compõem a obra, encontramos narrativas bastante lidas e estudadas, encontramos também outras pouco visadas pelas análises mais formais, sendo por isso mesmo menos divulgadas. Nesse segundo grupo está aquela que escolhemos abordar. Portanto, este estudo tem por objetivo destacar a relevância desse conto na obra da qual é parte integrante e o quanto é significativa a sua análise. Trata-se de "Chasque do Imperador", aquele que acaba sendo citado, ou identificado, muitas vezes, como $o$ da piada dos docinhos, e referido como um de menor importância. No entanto, em se tratando de Simões Lopes Neto devemos ter sempre em mente que há algo além das aparências e que a busca é válida. Após a releitura do texto, constatamos que este não é um conto como os outros dentro dos Contos gauchescos. Trata-se de uma narrativa que fica um pouco esquecida, pois os contos que mais ensejam estudos são os mais impressionantes, ou mais atraentes do ponto de vista dramático - aqueles cuja trama agrega elementos trágicos e/ou passionais, batalhas e sangue derramado -, e esse parece ser quase uma mera curiosidade. Percebemos, porém, que ele revela uma complexidade maior em uma leitura mais atenta.

O enredo do conto é simples, começa com o narrador, Blau Nunes, gaúcho octogenário, mas ainda forte, vivaz e de excelente memória, contando episódios, fatos que ele julga inusitados e dos quais participou em sua maturidade. Fala de sua experiência militar e das figuras importantes que conheceu e as quais serviu. Esses episódios são breves, narrados com certo orgulho a modo de causos que visam a audiência de um determinado interlocutor, 
sujeito letrado que percorre o interior da região pampeana acompanhado por Blau. São episódios encadeados, formando uma seqüência que culmina com o famoso caso dos docinhos, que teriam sido oferecidos por um determinado sujeito mui gauchão, fazendeiro ou charqueador, ao seu hóspede ilustre: o Imperador D. Pedro II. Tendo ouvido contar que as gentes da corte só se alimentavam de 'finuras', esse sujeito oferece ao Imperador, por dias seguidos, apenas docinhos finos e chá. Até o dia em que o hóspede, não mais suportando provar alguns por educação, e não agüentando mais a fome, protesta educadamente, elogiando os doces, mas solicitando um 'feijãozinho ou uma lasca de carne', provocando o alívio - e o respeito - de seu hospedeiro que até então, por gentileza e hospitalidade, lhe fazia companhia nos docinhos, mas que agora lhe oferecia, alegremente, um churrasco.

Então, o que há nesse conto além da história/piada dos docinhos? Em uma primeira abordagem, três detalhes chamam a nossa atenção em o "Chasque do Imperador", causando uma sensação de estranhamento. A primeira impressão é de que ele é diferente e que destoa da maior parte dos contos do autor. A segunda é a de que falta alguma coisa - o que está relacionado à nossa intuição do que deve ser um conto. Por último, notamos que há nele uma certa graça, que o torna despretensioso, leve, quase um intervalo, uma trégua na matança que o cerca. Buscando as razões para que tal fato se dê, constatamos que a temática do conto não o distingue dos demais, nem do restante da obra de João Simões Lopes Neto. Investigamos, então, a estrutura da narrativa, os seus aspectos formais, procurando os prováveis motivos da diferença sentida.

Uma segunda leitura revela sempre muito mais, pois o nosso interesse pelo que acontece na história, pelo evento, já foi satisfeito. E essa segunda leitura deixa evidente que apenas na aparência "Chasque do Imperador" é simples, pois, do ponto de vista literário ele é até mesmo sofisticado. Estruturado a partir de micronarrativas ( $2^{\mathrm{a}}$ parte), introduzidas pela situação do local, do tempo, e das personagens ( $1^{\mathrm{a}}$ parte), conta com um narrador/contador em primeira pessoa. Observamos, também, a presença de um interlocutor que não se manifesta em voz narrativa, mas isso nós sabemos mais porque conhecemos o conjunto da obra, já que no desenrolar da trama, uma única vez o narrador se dirige a esse interlocutor: "E vancê creia..." (p. 57), a quem conta causos de quando foi soldado e esteve a serviço do General Caxias e do Imperador Pedro II. De qualquer forma, é evidente que se trata de uma história que está sendo contada a alguém, pois esse narrador faz uso de recursos característicos de um contador de estórias, seja para situar o palco e o tempo da ação da história que irá contar: “Quando foi do cerco de Uruguaiana [...]”(p.55), ou para dar início à narração dos fatos que presenciou ou viveu: “Começou assim: [...]”(p.55), seja para provocar efeito de suspense: 
"Quem seria?[...]"(p. 56), ou mesmo como recurso de introdução à seqüência de seis micronarrativas que se constituem em anedotas ou chistes: "E a bem boas assisti." (p.58). Cada uma dessas micronarrativas tem, também, uma introdução que lhes corresponde: 1“Um dia [...]”(p.58); 2 - “Outro, no meio da roda, [...]”(p.58); 3 - "Havia um que era barão [...]"(p58.); 4 - "Este mesmo barão, duma feita [...]"(p.58); 5 - "Numa das marchas [...]"(p.59); 6 - "Numa cidade onde pousamos [...]"(p.60).

A caracterização desse narrador nos remete a uma das categorias fundamentais estabelecidas por Walter Benjamin (1994), o marinheiro comerciante, à qual o autor opõe uma outra, a do camponês sedentário. É fato, o narrar está intimamente relacionado à sabedoria, à perpetuação da memória e identidade de um povo, e é esse papel fundamental que representa o contar de Blau Nunes nos Contos gauchescos, uma narrativa "tecida na fala rememorante e truncada, que conta, questiona e se espanta, se aprendendo ao narrar" (LEITE, 1988, p.342), espécie de inventário histórico e social da região que agoniza, que se transforma, e do tipo humano que se adapta (ou tenta) a essas transformações. Destaque-se que o interlocutor a quem se dirige o narrador dos contos faz anotações, o que pressupõe a perpetuação dessa memória sob a forma escrita.

As qualidades tidas como típicas do gaúcho - a lealdade, a honra, valentia - se fazem presentes no Chasque do Imperador, porém desmistificadas. Há referência ao mito do gaúcho, mas diríamos que essa referência, apesar de parecer reforçá-lo, na verdade o desconstrói, pois apresenta o gaúcho sobretudo como um ingênuo - e meio gozador, por conta dos seis pequenos chistes, voluntários ou não, que compõem a narrativa. O gaúcho, aqui, desce do cavalo, não há evidências da imponência com que habitualmente é retratado nos textos de temática regionalista. A idéia que se pode fazer de Blau Nunes, nesse conto, não é a que temos dele pela leitura dos outros, sua imagem é diversa daquela a qual nos acostumamos, já que aqui ele perde, tanto quanto os outros gaúchos, não apenas a imponência, mas também a aura de sabedoria e a sisudez. É retratado também como falastrão - sendo inclusive interrompido por Caxias - e excessivamente servil, comportamento que poderíamos atribuir à sua juventude. Porém, se as contas que faz Flávio Loureiro Chaves (1982) estão corretas, e acreditamos que estejam, se Blau nasce em 1817, e o conto se passa em 1865, como indicado no próprio texto, teria ele, então, 48 anos, o que invalida a tese. Ele próprio, por vezes, diminui-se, mas pode ser caso de falsa modéstia: "Cada um, firme como um tarumã; as guascas, das melhores, as garras, bem postas, os metais, reluzindo; os fletes tosados a preceito, a cascaria aparada... e em cima de tudo, - tirante eu - uma indiada macanuda [...]" (LOPES NETO, 1983a, p.55). 
Blau fala da convivência com os graúdos procurando demonstrar pouco caso, mas deixa transparecer uma certa vaidade por servi-los: "De tardezita já entrava de serviço. A não ser nas conversas particulares daqueles graúdos - pois tudo era só seu barão, seu conselheiro, seu visconde, seu ministro -, eu sempre via e ouvia o que se passava." (LOPES NETO, 1983a, p.58).

Ocorre, também, a desmistificação da nobreza. Tanto quanto o gaúcho, o Imperador se humaniza, o que nos faz lembrar do sentido pejorativo comumente atribuído à palavra desmistificação:

Eu pensava que o Imperador era um homem diferente dos outros, assim todo de ouro, todo de brilhantes, com olhos de pedras finas... Mas, não senhor, era um homem de carne e osso, igual aos outros... mas como quera... uma cara tão séria... e um jeito ao mesmo tempo tão sereno e tão mandador, que deixava um qualquer de rédea no chão!... Isso é que era! (LOPES NETO, 1983a, p.57)

Tudo é muito pitoresco e todos são muito simples no Chasque do Imperador. Mesmo que Blau Nunes se refira à aura de poder que emana do Imperador, tanto este, quanto o gaúcho, as autoridades, ou a velha senhora, são humanos. A frase pronunciada pelo Imperador: "Como é agradável essa rudeza tão franca!" (p.60), resume esse clima de humanidade meio ingênuo do conto. Também a forma como o estrangeiro é retratado equivale a dos outros contos, e à obra de Simões Lopes, em geral. Trata-se sempre de algum gringo meio maricas ou um fracote de voz fina:

\footnotetext{
$\mathrm{Na}$ testa vinha um homem alto, barbudo, ruivo de olhos azuis, pequenos, mas mui macios [...] assim a modo de um gringo, [...] (LOPES NETO, 1983a, p.56)

Vai então, o tal, que pelo visto era mesmo o tão falado Imperador, disse, numa vozinha fina: [...] (LOPES NETO, 1983a, p.57)

O Imperador - esse era meio maricas, - era! (LOPES NETO, 1983a, p.60)
}

Após essa breve incursão pela estrutura do conto, buscando os elementos que o constituem, voltamos às questões que colocamos no início desse estudo, a fim de respondêlas. Em relação à primeira delas: Por que ele é diferente?, constatamos que essas diferenças se evidenciam pelo que conhecemos do conjunto da obra de Simões Lopes, mais especificamente os Contos gauchescos, e pelo que sabemos da Forma Conto. Observamos que o conto "Chasque do Imperador" não evolui como os demais da obra da qual faz parte, pois mesmo aqueles que se destacam pela presença do humor, como "Melancia coco-verde" ou "Deve um queijo", têm um enredo e uma estrutura de conto, o que não é o caso daquele que analisamos. Isso nos leva à segunda questão: $O$ que falta nele?. Diríamos que o que se dá nesse caso é que, por sabermos intuitivamente o que é um conto, acabamos tomando a última anedota como o conto todo, já que esta apresenta uma estrutura bastante próxima da forma 
conhecida. Singularmente, o conto todo se transforma na história dos docinhos, pois quando nos perguntamos sobre o acontecimento - o que acontece na estória? - automaticamente nos remetemos para esse evento que, além de ser o último, é o mais expressivo, aquele que causa 'o' efeito. "Chasque do Imperador" dá a impressão de um conto de transição, com a intenção de fazer graça. Quando alguém diz, 'vou contar uma história', procuramos, mesmo que não percebamos, a Forma do Conto, ou seja, uma narrativa breve, constituída de um único evento, com ou sem moral implícita (geralmente com), porém sempre próxima da oralidade, havendo em sua construção a intenção de efeito singular, que causa forte impressão e impacto quando de sua leitura.

Ao falarmos em moral implícita (ou explícita), nos referimos especificamente, mas não exclusivamente, ao Conto Popular - o conto maravilhoso, o conto de fadas, a fábula, aquela Forma que visa à satisfação do que André Jolles (1976) denomina nossa moral ingênua, a idéia de que tudo deva passar-se no universo de acordo com nossa expectativa, como gostaríamos que acontecesse no universo, como deveria acontecer. Para Christoph Martin Wieland, ainda, "o conto é um amálgama de duas tendências humanas, aquela que busca o verdadeiro e o natural e a que corresponde ao anseio de maravilhoso" (WIELAND, apud. JOLLES, 1976, p.191). André Jolles, em seu estudo sobre a Forma Conto, afirma que nos contos, a virtude é sempre recompensada e o vício punido, mesmo que suas personagens e aventuras não nos propiciem a impressão de serem verdadeiramente morais. É a disposição mental específica da Forma Conto. O que podemos comprovar, por exemplo, em "Uma estória de amor (A festa de Manuelzão)", uma das novelas de Corpo de Baile (ROSA, 1960), na qual Guimarães Rosa trata metaliterariamente do tema em questão. A personagem contadora de estórias, Joana Xaviel, ao final de um de seus contares, protagonizado por Destemida, uma voluntariosa e impiedosa mulher, ao contrário do habitual, deixa insatisfeitos seus ouvintes.

A estória se acabava aí, de-repentemente, com o mal não tendo castigo, a Destemida graduada de rica, subida por si, na vantagem, às triunfâncias. Todos que ouviam, estranhavam muito: estória desigual das outras, danada de diversa. Mas essa estória estava errada, não era tôda! Ah, ela tinha de ter outra parte - faltava a segunda parte? A Joana Xaviel dizi que não, que assim era que sabia, não havia doutra maneira. Mentira dela? A ver que sabia o resto, mas se esquecendo, escondendo. Mas - uma segunda parte, o final - tinha de ter! Um dia, se apertasse com a Joana Xaviel, à brava, agatanhal, e ela teria que discorrer o faltante. Ou, então, por aí fundo, todo longe, pelos ôcos e veredas do mundo Gerais, caçando - para se indagar - cada uma das velhas pessôas que conservavam as estórias. Quem inventou o formado, quem por tão primeiro descobriu o vulto de idéia das estórias? Mas, ainda que nem não se achasse mais a outra parte, a gente podia, carecia de nela acreditar, mesmo assim sem ouvir, sem ver, sem saber. Só essa parte é que era importante. (ROSA, 1960, p.105-106) 
Há uma expectativa a ser satisfeita quando lemos ou escutamos uma história. No entanto, o "Chasque do Imperador", bem como os Contos gauchescos, apesar de sua temática popular, da linguagem regional e de sua proximidade com a oralidade, não é Conto Popular. Ainda assim, há a expectativa de que ele se encaixe na estrutura que lhe é correspondente. Portanto, trata-se realmente de um Conto? Do ponto de vista estrutural, não exatamente, se considerarmos o que por tradição se tem por Conto. Porém, ele nos deixa a satisfação de que seja um Conto, e é aí que reside a sua sofisticação, pois o autor estrategicamente reserva para o final a anedota mais interessante. A seqüência delas, em gradação, culmina na história dos docinhos, e na aceitação final do Imperador, por parte dos nativos - já que até então ele era chamado de maricas, apesar da sua já referida aura de poder a que alude Blau -, porque ele gosta de carne: "Pois vossa majestade come carne?!" (LOPES NETO, 1983a, p.60).

A evolução da trama acaba por puxar o conto para a última anedota - a qual não deixa de ser um mini conto - deixando a sensação - e a satisfação - de que seja Conto. E é o autor, a partir de recursos estilísticos, que nos induz a tomar esse rumo, manipulando nossa intuição. Não fosse por essa particularidade, que o faz atípico, "Chasque do Imperador" poderia ser considerado meio-conto, meio-causo, situado a meio caminho entre os Contos gauchescos e os Casos do Romualdo (LOPES NETO, 1983b), e só não é exatamente um causo, ou uma reunião de causos, porque o autor dá a ele tratamento literário, aproximando-o do Conto conforme o concebemos.

No que diz respeito a tratamento literário, João Simões Lopes Neto é pioneiro no uso de alguns recursos. Dentre aqueles utilizados pelo autor em sua obra, estão soluções narrativas adotadas posteriormente por outros autores, como Guimarães Rosa e Moacyr Scliar, por exemplo, caso do interlocutor mudo, que Simões Lopes Neto coloca em cena com Blau Nunes. Tal recurso é aproveitado pelo autor mineiro, que sabidamente teve acesso à obra de seu precursor, a fim de resolver problema semelhante na criação do Grande Sertão: veredas (ROSA, 1970). Assim, Riobaldo tem o interlocutor que necessita para o desfiar de suas memórias. Já o gaúcho Scliar se vale do mesmo recurso em Mês de cães danados (SCLIAR, 1977), como contraponto à fala de Mario Picucha - narrador/contador/protagonista -, criando um efeito adicional, a tensão, e introduzindo um novo elemento, o interlocutor deve pagar para ouvir as histórias do contador. Configura-se assim a revolução simoniana, ainda nos primeiros anos do século XX.

Portanto, a partir do que observamos, constata-se que "Chasque do Imperador", no conjunto dos Contos gauchescos, não destoa tanto quanto possa parecer à primeira leitura, pois se insere não só na temática da obra, como também pode ser situado na seqüência da vida 
de Blau ou, no Romance de Blau, que é a forma como Flávio Loureiro Chaves (1982) vê esse conjunto, dada a sua unidade, malgrado a seqüência não-cronológica dos episódios. Romance, ou Novelas de Blau, diríamos, e talvez o termo novela seja mais apropriado, se formos considerar a definição da novela original, surgida no século XIV - a novela toscana, a qual dá origem a Forma Conto (JOLLES, 1976, p.188-191). Adotando esse ponto de vista, o próprio conto poderia ser considerado uma mininovela, já que está estruturado em micronarrativas/anedotas, emolduradas pelo narrador e pelo tema - causos de soldado presenciados ou vividos pelo narrador na época em que servia ao Exército, quando, em determinada ocasião, foi também chasque do Imperador.

Certamente, foi observado que, até aqui, tratamos anedota e chiste como sinônimos. $\mathrm{Na}$ verdade não são, e reservamos essa observação para o momento em que chegamos, finalmente, ao terceiro motivo de estranhamento quando da leitura do "Chasque do Imperador": a presença do humor, a graça, a leveza que se fazem presentes, e que são aspectos relevantes a considerar.

Vladimir Propp (1992), tratando das manifestações do cômico, nos diz que é preciso estabelecer a sua especificidade, portanto, cada caso deve ser considerado isoladamente. Tecendo considerações sobre a atitude negativa em relação ao cômico, manifesta pelos idealistas do século XIX, que o viam como algo baixo, associado à matéria, ao corpo, em oposição e contradição ao belo e ao sublime, o autor chega ao comentário da teoria dos dois aspectos do cômico, informando que esta divide o cômico em dois pólos opostos: a comicidade de ordem superior e a de ordem inferior, sendo que as definições para este último são sempre insatisfatórias.

Mikhail Bakhtin vê a paródia como rebaixamento, em seu estudo da obra de Rabelais (2002), informa que este recorre às fontes populares, destacando o grotesco. Evidentemente, o teórico russo considera o riso e a cultura popular da praça pública, e critica aqueles que não o fazem, sobretudo os mesmos idealistas alemães a que se refere Propp, salientando que, na Idade Média, o riso tinha importância considerável. Porém, o autor certamente não teve acesso à obra de Guimarães Rosa, onde se faz evidente que esse rebaixamento não produz um efeito grotesco, mas antes um efeito reverso, obtido pelo trabalho com a linguagem, mais especificamente pela poesia contida nessa linguagem. Na obra rosiana o grotesco, transfigurado pela linguagem é elevado à categoria do sublime, promovendo, mesmo, uma exacerbação do sublime.

Estabelecendo uma diferença entre essas duas formas, diríamos que o chiste, consiste sobretudo em um gracejo, um dito de espírito, jogo de palavras, (a palavra é, justamente, 
fundamental no chiste), o humor se apresenta de forma mais sutil. Trata-se de humor propriamente dito. Já na anedota, o humor é mais aberto, mais escrachado, por vezes podendo chegar ao grotesco. Encontramo-nos, aqui, no terreno do cômico. A propósito dessas distinções, diz Guimarães Rosa, no $1^{\circ}$ prefácio de Tutaméia (1967):

No terreno do humour, imenso em confins vários, pressentem-se mui hábeis pontos e caminhos. E que na prática de arte, comicidade e humorismo atuem como catalisadores ou sensibilizantes ao alegórico espiritual e ao não-prosaico, é verdade que se confere de modo grande. (ROSA, 1967, p.3)

Diz ainda que "não é o chiste rasa coisa ordinária; tanto seja porque escancha os planos da lógica, propondo-nos realidade superior e dimensões para mágicos novos sistemas de pensamento." (ROSA, 1967, p.3). Na obra de Guimarães Rosa, a ocorrência do humor caracteriza-se, inclusive, como um de seus motivos, segundo o próprio autor, que assim o afirma nesse primeiro prefácio de Tutaméia. De acordo com Lélia Parreira Duarte (2001), essa particularidade pode ser detectada já em seus primeiros escritos, e se desdobra, abrindo novas possibilidades de significação.

A presença do humor na literatura não a torna menos nobre, e a obra do autor mineiro comprova o argumento tanto quanto a do outro João, o Simões Lopes Neto. A aproximação com Guimarães Rosa se justifica. Cláudio Cruz (1999), por exemplo, afirma:

é cada vez mais comum citar-se lado a lado, como representantes do melhor exemplo de um regionalismo arejado, liberto das peias do particularismo e aberto aos valores universais, - uma espécie de super-regionalismo, como o chamou Antonio Candido - os escritores João Simões Lopes Neto e João Guimarães Rosa. (CRUZ, 1999, p.11)

No universo simoniano, o humor se manifesta sob mais de uma forma. Nos Contos gauchescos, são quatro os contos onde essa presença se faz de forma mais evidente, caso do "Chasque do Imperador", "Deve um queijo", "O mate do João Cardoso" e "Melancia-Coco verde”. De qualquer forma, nos contos essa presença é mais sutil e, às vezes, irônica, ou uma zombaria, formas encontradas em "Chasque do Imperador", malgrado a presença de "expedientes tradicionais da sátira e do burlesco na desmistificação e rebaixamento dos Grandes", especialmente no recurso de se chegar a descoberta da humanidade do Imperador através das necessidades vitais e corriqueiras do ser humano, como a necessidade de alimentação normal, fato destacado por Lígia Chiappini Leite (1988, p.378), valendo-se dos estudos de Mikhail Bakhtin sobre a obra de Rabelais.

Já nos Casos do Romualdo, é a anedota é que se destaca, a sátira aberta, "as artes e artimanhas do puro riso", abafando, no entanto, o pranto que "às vezes, sorrateiramente, teima em querer ele mesmo passar de contrabando". (LEITE, 1988, p.379). 
Definitivamente, o fato de uma narrativa se apresentar humorística ou satírica, como afirmamos, não a desmerece, não a faz exemplo de literatura menor, pelo contrário, pois por vezes seus efeitos são opostos àqueles que esperamos ou supomos. Por vezes, também, não os percebemos. São recursos de que podemos nos valer, também, para fins que a princípio poderíamos julgar inadequados, como na construção de narrativas ligadas à questão identitária ou histórica, conforme observamos em "Chasque do Imperador", que é exemplar e assim comprova o argumento.

\section{Referências}

BAKHTIN, Mikhail. A cultura popular na Idade Média e no Renascimento - O contexto de François Rabelais. São Paulo:Hucitec/Anna Blumme, 2002.

BENJAMIN, Walter. O narrador - Considerações sobre a obra de Nikolai Leskov. In: Magia e técnica, arte e política: ensaios sobre literatura e história da cultura. São Paulo: Brasiliense, 1994. p.197-221.

CRUZ, Cláudio. Simões Lopes Neto a mancheias. In: CRUZ, Cláudio (org.) Cadernos Porto \& Virgula n. 17 - Simões Lopes Neto. Porto Alegre: UE/Porto Alegre, 1999. p. 11-14.

CHAVES, Flávio Loureiro. Simões Lopes Neto: Regionalismo \& Literatura. Porto Alegre: Mercado Aberto, 1982.

DUARTE, Lélia Parreira. Não já e ainda não: a leveza do humor em Guimarães Rosa. In: DUARTE, Lélia Parreira, ALVES, Maria Theresa Abelha. (org.) Outras margens Estudos da obra de Guimarães Rosa. Belo Horizonte: Autêntica, 2001. p.99-116.

JOLLES, André. O conto. In:___. As Formas Simples. São Paulo: Cultrix, 1976. p. 181-204.

LEITE, Lígia Chiappini Moraes. No entretanto dos tempos - Literatura e História em João Simões Lopes Neto. São Paulo: Martins Fontes, 1988.

LOPES NETO, João Simões. Contos gauchescos. 18. ed. Porto Alegre: Globo, 1983. . Casos do Romualdo. 6. ed. Porto Alegre: Globo, 1983.

PROPP, Vladimir. Comicidade e riso. São Paulo: Ática, 1992.

ROSA, João Guimarães. Uma estória de amor ("A festa de Manuelzão"). In: Corpo de baile. 2. ed. Rio de Janeiro: José Olympio, 1960. p.84-152.

. Grande Sertão Veredas. 7. ed. Rio de Janeiro: Livraria José Olympio, 1970. . Tutaméia. Rio de Janeiro: Nova Fronteira, 1967.

SCLIAR, Moacyr. Mês de cães danados. Porto Alegre: L\&PM, 1977. 